Article

\title{
Taking Care of the Other: Visions of a Caring Integration in Female Refugee Support Work
}

\author{
Sophia Schmid \\ Berlin Institute for Integration and Migration Research, Humboldt University of Berlin, 10099 Berlin, Germany; \\ E-Mail: schmidso@hu-berlin.de
}

Submitted: 11 January 2019 | Accepted: 22 March 2019 | Published: 27 June 2019

\begin{abstract}
European societies have been significantly challenged recently by intensifying debates around migration and integration. In Germany, the controversy around refugees has put the question of how to negotiate cultural differences back on the agenda. This article argues that female refugee support work volunteers in Germany have developed a compelling approach to handling cultural diversity in emotional, social and cultural practices. Building on interviews with female volunteers, this article demonstrates that research subjects' interaction with refugees is guided by an 'ethics of care'. Care ethics is characterised by the recognition of interdependence and relationships, attention to the context and to the particular, blurring of the public and the private and orientation towards the needs of others. The research subjects show that care values, such as responsibility and attentiveness, can serve as an alternative framework to integration and to the negotiation of diversity in everyday encounters. Data from quantitative studies on refugee support work in Germany then reveals that female volunteers politicise their care work to respond to racism and right-wing xenophobia. Ultimately, a political ethics of care has the potential to structurally, politically and emotionally change established understandings of integration and the relations between host societies and immigrants.
\end{abstract}

\section{Keywords}

cultural difference; ethics of care; Germany; integration; refugees

\section{Issue}

This article is part of the issue "The European Refugee Controversy: Civil Solidarity, Cultural Imaginaries and Political Change", edited by Gert Verschraegen (University of Antwerp, Belgium) and Robin Vandevoordt (University of Oxford, UK/University of Antwerp, Belgium).

(C) 2019 by the author; licensee Cogitatio (Lisbon, Portugal). This article is licensed under a Creative Commons Attribution 4.0 International License (CC BY).

\section{Introduction}

In 2018 Germany's Minister of the Interior Horst Seehofer boldly declared "migration is the mother of all problems", causing an enormous stir among the German public. While right-wing and conservative opponents of immigration rejoiced, a union of the creative and cultural industries, migrant organisations and prominent politicians, even from Seehofer's own party, forcefully condemned the statement. This incident illustrated that in Germany, as in many other countries, heated debates on immigration and integration dominate the public discourse. The question of how to handle cultural differences remains a hotly debated issue that is still unresolved. This article enters the debate with a new perspec- tive on the possibility of emotional acceptance of diversity. It argues that the feminist ethics of care provides a unique opportunity to render integration practices more compassionate, just and inclusive.

Developed in the 1980s, the ethics of care describes an alternative moral approach to traditional ethics that centres on relationships, responsibility and interdependence (Robinson, 2010). Scholars such as Joan Tronto (1993) and Selma Sevenhuijsen (1998) expanded its scope by outlining the implications of care for political and societal transformation. Others also demonstrated how care ethics can facilitate the relationship to other cultural groups, both at home and abroad (Held, 2005; Robinson, 1997; Scuzzarello, 2015; Sevenhuijsen, 1998). This article builds on these insights to demonstrate how 
care ethics could structurally change political propositions on integration and the societal negotiation of cultural difference.

For this purpose, I define integration as a process of social, cultural, structural and emotional/identificational inclusion and recognition, which involves both immigrants and the host society (Foroutan \& Canan, 2016; Heckmann, 2015). While acknowledging structural and systemic barriers to integration, this article mainly focuses on emotional conflicts resulting from cultural difference. Cultural difference here stands for the diversity of social groups' norms, values, worldviews, beliefs and the resulting behaviours and practices which form a shared and historical system of meaning (Parekh, 2000). Following Stuart Hall (1996), I understand culture as a complex, ambiguous and constantly shifting social construct intersected by various other social dimensions such as gender or class.

Care-oriented integration is based on contextdependent and respectful dialogue that truly includes all voices, especially those that have so far been excluded in public discourse. Care values such as attentiveness, responsibility and responsiveness help recognise each individual's specific needs and design sensitive and flexible integration policies. Social relations characterised by these values could evoke empathy, trust and solidarity between immigrants and the host society and thus contribute to social cohesion and harmonious intercultural relations. This article provides a practical and empirical example of what a care-oriented approach to integration might look like in practice through interviews with female volunteers in refugee support work.

After briefly outlining the current resentment of immigrants and cultural difference and why established concepts like multiculturalism fall short of providing a resolution, this article describes the central characteristics of the ethics of care. It then outlines a caring approach towards integration and cultural difference based on care-ethical principles in the political field. An empirical component, mainly analysing 22 qualitative interviews, follows which demonstrates how German female volunteers in refugee support work draw on the ethics of care to provide attentive and respectful care for refugees and interpret their voluntary care work as a political tool to achieve social change for more tolerance and openness towards refugees. Concluding this article is a discussion that consolidates the idea of 'caring integration' and considers various suggestions for policy change in current integration politics.

\section{The Debate on Cultural Difference and Refugees}

All over the world, immigration seems to be the issue of the hour. Many major political decisions in the last years, such as the election of Donald Trump for US president or the decision of the UK to leave the European Union, were substantially driven by concerns and fears about immigration. Right-wing populists in particular tried to exploit the so-called 'refugee crisis' to gain electoral success.

However, in Germany, by contrast, the general public and the media seemed at first to be exceptionally open-minded towards refugees. This 'welcome culture' was particularly visible through the creation of new organisations and spontaneous initiatives supporting asylum seekers (for a comprehensive overview see Hamann \& Karakayali, 2016). As Karakayali (2018) maintained, the 'crisis' presented an opportunity for a large number of Germans to engage with migration first-hand. Indeed, Karakayali and Kleist (2016) revealed that the refugee support movement encompasses a broad crosssection of German society, including a large number of women and migrants. It also includes volunteers of all ages in urban and rural locations. Refugee support work not only represented a humanitarian care effort, it also provided a platform for often implicit political engagement (Fleischmann \& Steinhilper, 2017), as this article demonstrates. In contrast to the widespread celebration of this unprecedented effort to help refugees, some critical voices pointed to unequal power imbalances upholding gendered and racialised colonial stereotypes, discourses of 'deservingness' and the paternalism often implicated in refugee support work (Braun, 2017; Holmes \& Castañeda, 2016). Thus, refugee support work in Germany remains a complex and contradictory phenomenon, themes to which this article will add another perspective.

After an initial welcoming attitude to refugees in Germany, the discourse soon shifted to increasingly depict refugees as problems, threats and criminals (Vollmer \& Karakayali, 2018). Consequently, the prevailing feeling about immigration currently seems to be one of crisis (Dines, Montagna, \& Vacchelli, 2018). Building on longstanding resentment of cultural and racial differences, migrants and refugees are constructed as generalised threats to national security and culture. In this process, they become the principal targets for the myriad anxieties and rising discontent with politics in general (Holmes \& Castañeda, 2016). In Germany, this discourse has a particular appeal, as up until 2001, the country refused to accept realities of immigration. Germans have long constructed their national identity as ethnically and racially exclusive and thereby set apart migrant and particularly Muslim communities as 'other' (Foroutan \& Canan, 2016). In 2015, the influx of refugees led to a re-emphasis of this homogenous character of national belonging.

Moreover, as anti-immigration campaigns often include considerable backlash against multiculturalism and its proponents, the long-time dominant political frame for cultural diversity can be understood to be coming under fire too. Under the catchword of multiculturalism, rejection of difference as 'culture' has found its place where outward references to 'race' have become socially unacceptable (Lentin \& Titley, 2012). Originally, the concept of multiculturalism emerged as a re- 
action to minority groups' increasing demands for public recognition in Western societies-seeking to politically, socially and legally accommodate national and ethnic identities within liberal democracies (Kymlicka, 1995; Modood, 2007). Resting on the basis of universal equality, this 'politics of difference' still respects the plurality of unique identities and cultural diversity (Modood, 2007; Parekh, 2000; Taylor, 1994).

Leaving aside the populist criticism of multiculturalism, the academic critique above all questions multiculturalism's rigid, homogeneous and bounded identity categories (Lyshaug, 2004). A variety of scholars have argued that multiculturalism risks neglecting internal variations in continually contested, fluid ethnic identities, and the complex power relations between and within groups (Anthias \& Yuval-Davis, 1992; Hall, 1996; Scuzzarello, 2015). Consequently, a number of alternatives and further developments of multiculturalism have been proposed. This article aims to add the additional perspective of caring integration to academic discourses on multiculturalism. Some scholars of multiculturalism advanced 'interculturalism', which centres on intercultural dialogue and interaction to resolve multicultural conflicts (Meer \& Modood, 2012). As I will demonstrate, interculturalism echoes many central ideas of the ethics of care.

Particularly pertinent for care-ethical approaches to culture is feminist literature on multiculturalism. While many feminists do support multiculturalism's demand for the recognition of social groups to address structural inequalities (Young, 1990), they point towards multiculturalism's tendency to leave women vulnerable and unprotected when uncritically defending controversial practices of minority cultures (Okin, 1999). Some even claim that the multiculturalist celebration of diversity is a fantasy that obscures the real and systemic experience of racism (Ahmed, 2008). On a theoretical level, some feminists argue that more flexible, shifting and intersecting conceptualisations of identities illuminate the complex power dynamics between different categories of oppression such as race, class and gender (Anthias, 2002; Lyshaug, 2004). Interestingly, several care theorists draw on these scholars, particularly Iris Marion Young's work, to argue for the recognition of plurality inherent in care ethics and for a more complex model of responsibility (Conradi \& Heier, 2014; Sevenhuijsen, 1998; Tronto, 2013).

As will be demonstrated, the ethics of care also seeks to empower those currently excluded by uncovering the power relations that construct them as subordinate. Based on sensitive dialogue, the ethics of care calls for the genuine consideration of each individual's specific needs and contexts, thus concurring with the demand advanced by Anthias and Yuval-Davis (1992) and others to move beyond rigid and homogeneous assumptions of group needs. To conclude, this article suggests that the ethics of care offers a persuasive, yet relatively unexplored further perspective on new strategies facilitating the integration of immigrants.

\section{The Ethics of Care as a Key to Integration}

\subsection{The Care-Ethical Perspective}

Care as a disposition or ethical value is intimately linked to the understanding of care as a practice. While there is no general agreement on the definition of care, Fisher and Tronto's (1990) broad conceptualisation constitutes a popular foundation. They define care as:

A species activity that includes everything that we do to maintain, continue, and repair our 'world' so that we can live in it as well as possible. That world includes our bodies, our selves, and our environment, all of which we seek to interweave in a complex, lifesustaining web. (Fisher \& Tronto, 1990, p. 40)

Accordingly, care is a deeply human process based on interdependence and relationality that takes place in public and private. Tronto (1993) further divided the process of care into four phases: caring about (recognising the existence of a need), taking care of (assuming responsibility for this need), care-giving (meeting the need) and care-receiving (the response of the object of care).

The ethics of care, then, concentrates on the moral dimension emerging from caring relationships among individuals (Robinson, 1997). In the wake of second-wave feminism, Carol Gilligan (1982) first popularised care ethics when researching the ethical contemplations of children. Whereas boys drew on an 'ethics of justice' based on fairness, autonomy and rationality, for girls, relationships, empathy, concrete context and responsibility played a crucial role in their moral judgementwhat Gilligan termed an 'ethics of care'. While Gilligan's experiments could not always be replicated (Engster, 2007; Skoe, Cumberland, Eisenberg, Hansen, \& Perry, 2002), this 'first generation' of care ethicists was most profoundly criticised for reifying sexist gender stereotypes that confine women to the private sphere and the household (Hankivsky, 2014; Tronto, 1993). Gilligan (2011, p. 22) later addressed this criticism, however, when pointing out that "within a patriarchal framework, care is a feminine ethic. Within a democratic framework, care is a human ethic".

Consequently, the ethics of care developed into a multidisciplinary strand of feminist research expanding into a broad range of disciplines (Klaver, van Elst, \& Baart, 2014). Most conceptions of care ethics today have the following characteristics in common: the central importance of relationships, recognising the context and particularism, transcending the private sphere into the political, appreciating emotions as moral tools, and grounding ethics in the empirical practice of care (Engster \& Hamington, 2015; Klaver et al., 2014). Following the latter principle, Tronto (1993) deduced four fundamental ethical elements corresponding to the above-mentioned phases of care: attentiveness, responsibility, competence, and responsiveness. Other care ethicists have also 
emphasized the values of trust (Held, 2015), recognizing different points of view, empathy and compassion (Sevenhuijsen, 1998), and respect (Engster, 2007).

\subsection{Envisioning Care-Oriented Integration}

To utilise care-ethical insights for integration, this article mainly draws on the political re-orientation of feminist care ethicists of the second generation (Hankivsky, 2014), who aim at "developing a new political theory that can usefully guide analysis and action under contemporary conditions...[in an] increasingly interrelated and networked society" (Engster \& Hamington, 2015, p. 7).

The political ethics of care was pioneered by Joan Tronto (1993), who argued that care has the potential to transform society and public life and represents a crucial element of democracy (Conradi \& Heier, 2014). She added a fifth phase of care called 'caring with' that perceives citizens as interdependent and in need of care. Thus, 'caring with' shifts the main goal of politics "to ensure that all of the members of the society can live as well as possible by making the society as democratic as possible" (Tronto, 2013 , p. 30). Democratic caring is based on the values plurality, communication, trust and respect, and solidarity. Responsibility for democratic care expands and includes collective action as well (Conradi \& Heier, 2014).

Following Tronto, I maintain that care as a political theory needs to additionally inform ideas and practices of integration. Political care ethics is pivotal in today's superdiverse democracies faced with the challenge of cultural difference. Indeed, Engster (2007, p. 4) observed:

Care theorists have also thus far failed to address adequately the challenge of multiculturalism. Since most societies today are populated by individuals with diverse cultural and religious views, it is important to situate care ethics in relation to these diverse worldviews.

The following pages aim to contribute to closing this literature gap.

To begin, care values are particularly well equipped in dealing with diversity and difference. In Sevenhuijsen's (1998) model of care-oriented citizenship, processes of public deliberation respect each person's individual view and take into account specific contexts. She argued that care ethics avoids the problem of citizens having to conform to an unrealistic 'sameness', or a shared identity. Instead, it positively values difference and relations to others, in ways similar to multicultural discourse. This is particularly important for those most obviously different to mainstream society: immigrants and refugees. Sensitivity to both culturally specific caretaking practices and needs, and non-intervention if a basic standard of caring is met, characterise care in a complex, multicultural social context (Clark Miller, 2010; Engster, 2007). Attentive dialogue and recognition of interdependence would allow for more inclusive, flexible, decentralised and responsive policies that meet the needs and per- spectives of different individuals, supporting each citizen to live in society as well as possible (Engster, 2007; Sevenhuijsen, 2000).

By recognising today's complex global relationality, the ethics of care sheds light on and aims to reduce power imbalances. This is mainly done by empowering those without a voice and constructed as dependent on the global North (Robinson, 2010). By ideally listening to and taking seriously all voices, caring integration could potentially circumvent the ethnocentrism and paternalism that historically characterised Western attitudes towards other cultures (Held, 2005; Narayan, 1995). A caring integration that acknowledges racial and gendered inequalities hence involves formerly excluded actors in the public discourse and the shaping of public institutions (Conradi \& Heier, 2014). To avoid unequal power relations, Clark Miller (2010) further contended that feminist care ethics does not solely prioritise meeting needs, but more importantly seeks to restore agency so that individuals can care for themselves. As opposed to multiculturalism, "care theory privileges not only the generic features of caring over cultural values, but also the care of individuals over group values and goals" (Engster, 2007, p. 99). By undermining binary constructions and being sensitive to intersecting positionalities, caring integration advances multiculturalism's exclusive focus on ethnicity to a more particularised perspective including categories such as age, gender or class (Hankivsky, 2014; Sevenhuijsen, 1998).

According to Sevenhuijsen (1998, p. 15), a caring society is "capable of dealing with the radical alterity of human subjects, through recognizing their individuality and diversity while at the same time conceiving of them as equals". The latter becomes particularly important when confronting defenders of a 'shared identity', supposedly reducing antagonism by the dominant group. In contrast, care-ethical integration builds on civic caring virtues as a basis of societal interaction and cultivates emotional connection through empathy and trust towards those perceived as culturally different (Held, 2005). Care ethics transcends the personal or national frame, as the shared experience of being cared for has the potential to motivate even distant people to trust and respect each other. More explicitly, Clark Miller (2010) asserted that as fundamentally interdependent beings, we have a moral duty to care for each other individually, but also globally. This duty leads to caring relations within and between societies that encourage the solidarity underpinning welfare states and democratic institutions (Held, 2005). A caring global civil society rests on relationships between concrete individuals and attentiveness towards their real needs and replaces an abstract, impersonal and often unattractive cosmopolitanism (Robinson, 1997).

Engster (2007) further demonstrated how mutual dependency and the common experience of care provide a basis for intercultural dialogue and mutual obligation. As care ethics judges all cultural practices against the universal standard of good care, caring integration is partic- 
ularly well suited to discuss anti-democratic practices or controversial issues, such as the right to circumcision or wearing a headscarf. As long as they do not impede the provision of minimally adequate care, individuals should be free to keep their cultural practices.

The ethics of care has a number of merits compared to multiculturalism and interculturalism. Notably, Scuzzarello (2015, p. 73) outlined a 'caring multiculturalism' that "sees individual and collective identities as relational, processual, negotiated and political, and...analyses and attempts to change the gendered power asymmetries embedded in intra- and intergroup relations". Thus, caring multiculturalism replaces traditional multiculturalism's rigid, unidimensional understanding of group characteristics and neglect of power relations. As this article also argues, Scuzzarello (2015) advocated for contextsensitive, fully inclusive multicultural policies, informed by care values and based on the real needs of those affected. Moreover, Zembylas and Bozalek (2011) indicated that care ethics has much in common with interculturalism as both emphasise dialogue and relationships, but care ethics goes even further by taking into account power relations, mutual dependence, vulnerability and larger-scale structural inequalities. Furthermore, interculturalism still relies on culture as its main variable of analysis, as the name already suggests. An intersectional care focus brings to the forefront interacting social positionalities as well (Hankivsky, 2014).

While Scuzzarello, Zembylas and Bozalek have proposed ways to improve multiculturalism from a caring perspective, they remained on a fairly abstract level and thus failed to anchor theory in caring practices, a crucial element of the ethics of care. This article thus advances the theory of caring multiculturalism and integration by demonstrating what they could look like in practice. The following section traces how the ethics of care informs and influences relationships between the majority group and minority cultures in refugee support work.

\section{Methodology}

The following insights draw on 22 semi-structured faceto-face interviews with female refugee support work volunteers in four different locations in Germany-two bigger cities (Berlin, Hamburg) and two smaller towns. As attitudes towards refugees often seem more hostile in East Germany (Karakayali \& Kleist, 2016), one of these towns is located in West Germany and one in East Germany. The fieldwork took place between May and July 2018. The volunteers, aged between 20 and 70, came from various occupational positions (e.g., students, working professionals, pensioners). The research subjects were part of a variety of refugee support organisations, ranging from self-organised initiatives set up spontaneously in-or-after the summer of 2015 , to already established church- or school-based organisations that strengthened their existing efforts on refugee support work. Access to these research subjects was often gained through these organ- isations, with a coordinator or spokesperson forwarding my request and organising interviews, or through personally organised contacts. In a detailed initial letter, I highlighted my background and institutional connection, the aims of the research, the content of the interviews and ethical assurances, such as anonymity and data protection. Together with informed consent given prior to the interviews, this instruction contributed to the ethical soundness of the research. I was also open to answering any additional questions the participants might have, which a number of women made use of.

On average, the interviews lasted for roughly one hour, were conducted in German and concentrated on motivations to volunteer and prior expectations, descriptions of the voluntary work (including challenges or rewards), and the impact of the voluntary work on the women. Finally, topics such as integration, the current right-wing discourse or gender issues allowed for a more abstract, moral reflection. To avoid the reification of gender stereotypes, however, the latter were kept to a minimum and often emerged out of the participants' own accounts. Nevertheless, I followed Lofland's (1971) relatively open and flexible method of 'guided conversations' to more specifically focus on certain aspects when relevant or skip or change the order of the questions depending on the situation. While the research subjects were aware of the general objective of the study, researching volunteers' relations with refugees and their individual approach to refugee support work, I did not specify my theoretical approach of the ethics of care, as I both aimed to elicit unbiased, general and genuine responses and only developed the theoretical framework successively in a mix of inductive and deductive analysis. With consent, all interviews except one were digitally recorded and transcribed verbatim. The interviews were analysed successively with a detailed code frame based on the theoretical review that encompassed care values, careethical principles and Tronto's five phases of caring. To ensure the privacy and safety of the participants, this article omits names and other identifying information. All quotations have been translated from German into English by the author.

Before demonstrating how care-ethical values guide the relationship between female volunteers and refugees, it is crucial to point out that the following section only highlights instances where the volunteers succeeded in adopting a caring approach. While I use those as best practice examples for a model of caring integration, in my fieldwork I observed several behaviours and statements that directly contradicted the ethics of care that I analysed separately. Moreover, I cannot be certain whether the volunteers truly acted according to their beliefs and declarations in the interviews.

\section{Traces of the Ethics of Care in Refugee Support Work}

First and foremost, the interviews revealed that female volunteers centrally build on relationships, the funda- 
mental basis of the ethics of care. Many activities involved spending considerable time with refugees in sometimes relatively intimate settings. This includes, for example, accompanying refugees to doctor's appointments or court hearings, or tutoring children after school. As a result, the volunteers invariably developed close relationships and friendships with particular refugees, often highlighting the refugees' supposed emphasis on personal relationship as a cultural difference they admire most. They occasionally evoked family metaphors, for example in the sense of adopting refugees into the family and being seen as a part of the refugees' families:

You belong to the family, they don't do things halfway. They don't have this American mentality, come visit us some time. Rather, they either immediately reject you....Or they accept the help but then you're a family member, forever and ever.

\section{Or as another volunteer remarked:}

They are very happy that I visit them at home. That is a kind of friendship, I would say. Then you talk, the kids, we tell each other our worries...I get along very well especially with the mothers, because I am also a mother myself.

This close relationality had a number of effects, such as developing trust, recognising similar worries and caring needs, and giving rise to a vigorous solidarity that led some volunteers to passionately fight to defend refugees in court or to public authorities. Consequently, when the conversation turned to values they follow in their voluntary work, the volunteers experienced fundamental empathy and obligation towards others. The friendships the volunteers developed increased this empathy-informed obligation and often further strengthened their motivation. When asked whether she ever considered quitting, one volunteer responded:

Somehow that wasn't an option. I have the feeling, once you got to know these people and when you understood the kind of situation they are in....I was so much in this situation and somehow my whole life revolved around it.

The following selection of Tronto's, Sevenhuijsen's and Engster's care values played the most significant role in female refugee support work: attentiveness, responsibility, empathy, respecting different perspectives and respect. Attentiveness to the context and situation of each person in their particularity represents a central characteristic of caring integration. Similarly, instead of assuming a one-size-fits-all approach, the volunteers strived to understand the refugees' specific needs and to provide them with a sensitive and genuine solution. One participant, for example, recounted an instance where female volunteers collected cosmetics and similar femi- nine items overlooked by other volunteers as "you actually don't need them". They then brought this "women's box" of luxury items to the refugee shelter for female refugees. Another volunteer created a student research project with the aim of identifying the refugees' real needs, which resulted in the idea of an app that brought people together based on shared interests. Sometimes, when the women felt that services were not attentive enough towards the refugees' actual needs, they even stood up against the authorities or shelter operators.

Another value that played a central role in the women's voluntary work is responsibility. The importance of responsibility stood out most when the research subjects tried to explain their motivation to become involved in refugee support work. Repeatedly, they struggled to provide concrete answers and claimed that they just had to, that they saw an appeal for help or that the sheer presence of the refugees was enough for them to assume responsibility without many other considerations. One volunteer summed this up as follows:

Whenever people and their social circumstances are involved, regardless of their background, I feel addressed. It was a very intense situation, an unexpected situation. You could almost say, actually, it was a crisis situation. And the first thing I thought of was, you have to do something. Many people just talked about it. But I had the feeling that you also really have to practically do something.

More specifically, some volunteers felt that their comparative wealth and privilege created a moral obligation to help those that are less well-off. This responsibility often sprung from the perception of shared humanity or humanitarian values connected to Sevenhuijsen's (1998) values of empathy and compassion. Some volunteers, for instance, pointed out that they did not specifically choose to help refugees, but saw them as people that needed support in general and would have been equally willing to volunteer for other groups in need. Consequently, volunteers highlighted the importance of providing universal care while respecting different perspectives (Sevenhuijsen, 1998; Tronto, 2013):

Because I consider life very valuable, I find that everyone should have the right to lead a happy life. And what that looks like for one or another, everyone has to define that for themselves. But I think we have, life is a gift we have to be thankful for.... That's something that I want to achieve in my life, this right to freedom, to peace, to be accepted, to a home. Maybe also a new home. And protection.

Turning to the power relations inherent in any caring situation, a remarkable number of volunteers attached vital importance to treating the refugees respectfully-a value highlighted by Engster (2007) and Tronto (2013)as adults and 'on an equal footing'. This crucially in- 
volved attentive listening, perceiving them not primarily as refugees but as human beings, and appreciating different cultures and values. Many considered experiencing diverse perspectives a valuable reward of their voluntary work and subsequently started to question their own world-view and habits as well (see Sevenhuijsen, 1998).

This facet of caring refugee support work presents a suitable opportunity to further delve into the effectiveness of the care-ethical approach in conflictual intercultural situations, an aspect this article so far left aside. A very common aspect arising in almost all interviews was the experience of disappointment, anger or bewilderment when refugees did not show gratitude, did not conform to expected behaviours in their 'best interest' or even rejected the help of volunteers. Although these incidents often deeply affected the volunteers, many managed to overcome their hurt feelings and continue to help effectively by reminding themselves of their commitment to respect the refugees' individual standpoints and culture, and to be attentive to their complex and specific needs that are often obscured for those not similarly affected. Moreover, a care-ethical emphasis of relationships helped volunteers negotiate these situations when they sought talks with the other party or other volunteers. One volunteer recounted a fairly typical experience of helping to set up a flat for a refugee family. After she organised a number of essentials, such as mattresses for free, the family showed her a large flatscreen TV that they had just bought. Although the woman was deeply baffled and had to leave immediately, she later reflected the situation as follows:

My priorities don't always have to be the priorities of other people, you shouldn't mix that up. I don't have to make others happy the way I am happy. There are so many differences between people.....And why should I interfere? I would perceive this as too arrogant myself....But I was surprised, if I'm being honest, because I didn't consider myself so intolerant. These are moments when you question yourself.

To mitigate these power hierarchies and misunderstandings, many volunteers tried to involve the refugees as much as possible. Some saw their primary goal in capacity building and giving refugees agency, so that ultimately, they could take matters into their own hands and were not dependant on help any more. This constitutes a crucial requirement of both integration theory and care ethics.

Still, it is important to note that the immense power differentials in refugee support work continue to have an effect due to the volunteers' positionality as white majority group members. They possess structural advantages despite any potential efforts to counteract these or feeling threatened themselves. Here, Hankivsky's (2014) intersectional ethics of care might shed a light on the complex interactions between different oppressive power structures, in this case, particularly the influence of race on gender relations that the ethics of care has often disregarded. For example, this intersection manifested in some volunteers' often unfounded fear of sexual assault by male refugees or their intentions to 'emancipate' female refugees they constructed as oppressed, which both point to ethnosexual and orientalist power mechanisms of race and gender (Dietze, 2017).

\section{Potential for Structural and Political Change}

The political strand of the ethics of care radically challenges the boundary between the public and private to achieve more fundamental structural and political transformation. This article argues that refugee support care work has political potential as well. Apart from providing efficient, sensitive care for those culturally different, volunteers also use their care work as an alternative means of political participation and a tool for expressing their political beliefs. One young volunteer was of the opinion:

I don't think there's anyone who volunteers that doesn't also fundamentally have a political opinion on this....I do believe that it is a kind of statement to say, I play my part in helping here.

Ultimately, to a certain degree, the volunteers provide hints of how the idea of caring integration in their concrete work could also advance political approaches to refugees and immigrants in general. Interestingly, this political orientation has a strong gender component. This becomes apparent in the analysis of two quantitative surveys with German refugee support work volunteers from 2015 and 2016 with a total of 3,577 respondents that were contacted through German umbrella organisations in the field, thus ensuring limited sample selection bias. The results show that female volunteers are statistically significantly more likely to agree that through their voluntary work, they want to "take a stand against racism" (85\% of female volunteers fully agree versus $76 \%$ of males) and "show that, besides right-wing populism and violence, a welcome culture also exists/acting against right-wing mobilisation in my city/neighbourhood" (77\% of female volunteers fully agree versus $68 \%$ of males).

The qualitative interviews illuminate the concrete steps the volunteers took when aiming to establish caring integration approaches in their social environment more broadly. Being frustrated with how the refugee issue is currently handled politically, both on a local and national level, research subjects interpreted refugee support work as a particularly practice- and context-driven alternative to current policies and societal attitudes. As an illustration of alternative politics, some volunteers expressed consternation at the authorities' decisions on deportation. Instead of taking a refugees' whole situation into account, as the ethics of care would demand, research subjects perceived authorities as basing decisions on insensitive and highly generalised assumptions. Fear- 
ing the deportation of her Gambian charges, one volunteer proposed:

I understand that long-term, Gambians actually don't have a right to asylum. The dictatorship is officially abolished. Purely based on the law, I understand that they don't have a right to stay. But we need craftsmen, Germany too.... They would only need to ask different independent people. I don't know how to organise this, but there should be a system. They should ask three people of AK Asyl [the refugee support initiative], they should ask three people from the town administration, they should ask the lady from the administrative district office, they should ask the lady from the AWO [another welfare institution]. And obtain the information: who is at school, who works, who makes an effort, who integrates themselves.

Another strategy directed at changing social attitudes toward more tolerance consisted of activities in public or hostile environments where volunteers consciously presented themselves openly with refugees. These activities ranged from taking refugees to public recreation spaces, such as to a lake or to a Christmas market, to organising festivals or private parties where refugees were invited in particular. The volunteers hoped that thereby, they could show others who are not already open to other cultures that refugees pose no threat and in fact feel and act similarly, as well as providing an example themselves on how to deal with refugees. Especially in the small towns, the volunteers occasionally risked antagonism and personal animosity when directly confronting friends and family, but they felt they had an obligation to strengthen welcoming attitudes on a larger scale. Many women interviewed considered this direct contact and concrete relationships as the best measure to truly understand other cultures. In their opinion, this could then lead to a more peaceful and respectful social environment and reduce the current culture of hostility. Similarly to the quantitative findings, for some women, refugee support work also functioned as a communal symbol expressing that refugees are welcome, and that Germany has a friendly, open and compassionate side as well.

Thus, in line with Tronto's case for democratic caring, the volunteers interpreted their care work as an opportunity for deeper cultural and political change in Germany towards a more respectful and profound recognition of other cultural groups. While some volunteers interviewed had the feeling that they could, from the ground up, influence how some people in their environment thought about other cultures, others were rather pessimistic when faced with Germany's growing xenophobia. It remains to be seen whether caring refugee support work can lead to a long-term structural transformation of Germany's approach towards refugees, immigrants, and those perceived as 'other' in general. These topics, and others, are considered in the following sec- tion which analyses the consequences of a care-ethical approach to integration policies on a macro-level.

\section{Discussion}

On the basis of a political and multicultural ethics of care, and of the practice of care in German refugee support work, this article demonstrates how care ethics can enhance approaches to integration and cultural difference. The female volunteers interviewed showed how qualities such as respectful listening, taking into account the context and particular case, and assuming responsibility in concrete personal relationships, contribute to productive and amicable intercultural relations within a diverse society. Some of the volunteers related their care work to the public arena, hoping to achieve political and societal change as well. Hence, Tronto's (2013) conviction that care needs to become the centre of democratic politics also extends to contested social issues, such as integration. Basing social relations, citizenship practices and policies on care-ethical values has the potential to make political structures and the public sphere more inclusive both for immigrants and for other disenfranchised groups. Accordingly, Virginia Held (2015, p. 29) maintained that a global ethics of care "can contribute greatly to social change, to sensitivity toward and understanding of and willingness to take account of unfamiliar others and distant persons". In the long run, the ethics of care may provide a more effective framework for negotiating difference, cultural or otherwise, on a national and global level than current multicultural policies.

To conclude, I want to outline some potential implications for future research and political practice. This article substantiates care ethics' conflictive tension between demanding that all voices be heard but then only investigating and highlighting certain actors, mostly care givers, with a focus on Western practices (Lloyd, 2000; Narayan, 1995). Together with care's inherent danger of unequal power relations and paternalism (Williams, 2001), particularly in refugee support work, additional work on the perspective of refugees is urgently needed to do justice to the promise of a truly caring integration. This is critical towards illuminating the ambiguities, interrelations and conflicts that always accompany social negotiations from a feminist perspective. Additionally, this study purposely focused only on female volunteers and their specific approach to refugee support work. Thus, it inevitably relies on certain gender constructions that the ethics of care is based on. Studies on non-binary caring practices and ethics are sparse (Hines, 2007) and future research should challenge the gender stereotypes inherent in this approach.

As Scuzzarello (2015) and Zembylas and Bozalek (2011) suggested, multiculturalism and interculturalism could be re-examined to include more sensitivity to intergroup difference and power relations, as well as grounding theoretical considerations in the real-life practice of those affected. Turning to political and structural conse- 
quences of a caring integration, first and foremost, all voices need to become part of the political and public discourse. Apart from relying on experts and leaders of migrant community organisations, policymakers should make more of an effort to seek out the opinion of those not organised in any official institution or potentially silenced in the existing structures. This includes getting input from migrant women, queer people and children. Summits like the regularly occurring Islam conference in Germany can not only invite leading Islamic unions and prominent individuals, as it has often done in the past, but also a more diverse array of Muslims. Structurally, more low-threshold meeting spaces for policymakers, but more importantly ordinary citizens, should be created to develop personal relationships with immigrants and refugees.

To a certain degree, in the last years a number of civilsociety initiatives aiming to connect mainstream society with newcomers have already emerged, particularly in refugee support work. As the participants of this study reported, however, these initiatives usually only reach those already interested in and open to different cultures and do not extend into the social spheres where they are needed most. In personal interactions, those not yet open to other cultures could learn to respect different customs, as long as they do not impede on the provision of adequate care, through cultivating empathic connections. Regional governments in particular are thus called upon to create new local gathering structures and to ensure sufficient funding for broader outreach campaigns.

Focusing on the group that receives most public attention, Foroutan and Canan (2016) showed that the German public consistently questions Muslim religious rights and thus denies Muslim citizens their due recognition. As demonstrated in this article, caring integration could shift the discourse to an appreciation of culturally and religiously different caretaking practices, while at the same time safeguarding good care for vulnerable individuals within ethnic groups. Moreover, similarly to the way right-wing politicians and media induced a fundamentally anti-immigration and nationalist dominant stance since 2015, the German discourse could be shifted back to a more humane, caring and respectful mindset. Politicians, educational establishments and media outlets could introduce more solidarity and empathy based on care practices into public discourse by setting an example in formal and informal communications.

\section{Acknowledgments}

I thank Serhat Karakayali and Olaf J. Kleist from the Berlin Institute of Integration and Migration Research for granting me permission to use the data of two studies on voluntary refugee support work in Germany.

\section{Conflict of Interests}

The author declares no conflict of interests.

\section{References}

Ahmed, S. (2008). 'Liberal multiculturalism is the hegemony-It's an empirical fact': A response to Slavoj Žižek. Darkmatter. Retrieved from http://www.darkmatter101.org/site/2008/02/19

Anthias, F., \& Yuval-Davis, N. (1992). Racialized boundaries: Race, nation, gender, colour and class and the anti-racist struggle. London: Routledge.

Anthias, F. (2002). Beyond feminism and multiculturalism: Locating difference and the politics of location. Women's Studies International Forum, 25(3), 275-286.

Braun, K. (2017). Decolonial perspectives on charitable spaces of "welcome culture" in Germany. Social Inclusion, 5(3), 38-48.

Clark Miller, S. (2010). Cosmopolitan care. Ethics and Social Welfare, 4(2), 145-157.

Conradi, E., \& Heier, J. (2014). Towards a political theory of care. In G. Olthuis, H. Kohlen, \& J. Heier (Eds.), Moral boundaries redrawn: The significance of Joan Tronto's argument for political theory, professional ethics, and care as practice (pp. 29-50). Leuven: Peeters.

Dietze, G. (2017). Ethnosexismus: sex-mob-narrative um die kölner Sylvesternacht [Ethnosexism: Sex-mobnarratives around the night of New Year's Eve in Cologne]. Movements: Journal for Critical Migration and Border Regime Studies, 2(1), 177-185.

Dines, N., Montagna, N., \& Vacchelli, E. (2018). Beyond crisis talk: Interrogating migration and crises in Europe. Sociology, 52(3), 439-447.

Engster, D. (2007). The heart of justice: Care ethics and political theory. Oxford: Oxford University Press.

Engster, D., \& Hamington, M. (2015). Introduction. In D. Engster \& M. Hamington (Eds.), Care ethics and political theory (pp. 1-15). Oxford: Oxford University Press.

Fisher, B., \& Tronto, J. C. (1990). Toward a feminist theory of caring. In E. Abel \& M. Nelson (Eds.), Circles of care (pp. 36-54). Albany, NY: SUNY Press.

Fleischmann, L., \& Steinhilper, E. (2017). The myth of apolitical volunteering for refugees: German welcome culture and a new dispositif of helping. Social Inclusion, 5(3), 17-27.

Foroutan, N., \& Canan, C. (2016). The paradox of equal belonging of Muslims. Islamophobia Studies Journal, 3(2), 159-176.

Gilligan, C. (1982). In a different voice: Psychological theory and women's development. Cambridge, MA: Harvard University Press.

Gilligan, C. (2011). Joining the resistance. Cambridge, MA: Polity.

Hall, S. (1996). The question of cultural identity. In S. Hall, D. Held, D. Hubert, \& K. Thompson (Eds.), Modernity: An introduction to modern societies (pp. 595-634). Cambridge, MA: Wiley-Blackwell.

Hamann, U., \& Karakayali, S. (2016). Practicing Willkommenskultur: Migration and solidarity in Germany. In- 
tersections. East European Journal of Society and Politics, 2(4), 69-86.

Hankivsky, O. (2014). Rethinking care ethics: On the promise and potential of an intersectional analysis. American Political Science Review, 108(2), 252-264.

Heckmann, F. (2015). Integration: What makes it work? Bamberg: efms papers.

Held, V. (2005). The ethics of care: Personal, political, and global. Oxford: Oxford University Press.

Held, V. (2015). Care and justice, still. In D. Engster \& M. Hamington (Eds.), Care ethics and political theory (pp. 19-36). Oxford: Oxford University Press.

Hines, S. (2007). Transgendering care: Practices of care within transgender communities. Critical Social Policy, 27(4), 462-486.

Holmes, S. M., \& Castañeda, H. (2016). Representing the "European refugee crisis" in Germany and beyond: Deservingness and difference, life and death. American Ethnologist, 43, 12-24.

Karakayali, S. (2018). The Flüchtlingskrise in Germany: Crisis of the refugees, by the refugees, for the refugees. Sociology, 52(3), 606-611.

Karakayali, S., \& Kleist, J. O. (2016). EFA-Studie: Strukturen und Motive der ehrenamtlichen Flüchtlingsarbeit (EFA) in Deutschland: 1. Forschungsbericht: Ergebnisse einer explorativen Umfrage vom November/Dezember 2014 [EFA study: Structures and motives of voluntary refugee support work in Germany. First research report: Results of an explorative survey of November/December 2014]. Berlin: HumboldtUniversität zu Berlin.

Klaver, K., van Elst, E., \& Baart, A. J. (2014). Demarcation of the ethics of care as a discipline: Discussion article. Nursing Ethics, 21(7), 755-765.

Kymlicka, W. (1995). Multicultural citizenship: A liberal theory of minority rights. Oxford: Clarendon Press.

Lentin, A., \& Titley, G. (2012). The crisis of 'multiculturalism' in Europe: Mediated minarets, intolerable subjects. European Journal of Cultural Studies, 15(2), 123-138.

Lloyd, L. (2000). Caring about carers: Only half the picture? Critical Social Policy, 20(1), 136-150.

Lofland, J. (1971). Analyzing social settings: A guide to qualitative observation and analysis. Belmont: Wadsworth Publishing.

Lyshaug, B. (2004). Authenticity and the politics of identity: A critique of Charles Taylor's politics of recognition. Contemporary Political Theory, 3, 300-320.

Meer, N., \& Modood, T. (2012). How does interculturalism contrast with multiculturalism? Journal of Inter- cultural Studies, 33(2), 175-196.

Modood, T. (2007). Multiculturalism: A civic idea. Cambridge, MA: Polity Press.

Narayan, U. (1995). Colonialism and its others: Considerations on rights and care discourses. Hypatia, 10(2), 133-140.

Okin, S. M. (1999). Is multiculturalism bad for women? In S. M. Okin (Ed.), Is multiculturalism bad for women? (pp. 9-24). Princeton, NJ: Princeton University Press.

Parekh, B. (2000). Rethinking multiculturalism: Cultural diversity and political theory. London: Macmillan.

Robinson, F. (1997). Globalizing care: Ethics, feminist theory, and international relations. Alternatives, 22, 113-133.

Robinson, F. (2010). After liberalism in world politics? Towards an international political theory of care. Ethics and Social Welfare, 4(2), 130-144.

Scuzzarello, S. (2015). Caring multiculturalism: Power and transformation in diverse societies. Feminist Theory, $16(1), 67-86$.

Sevenhuijsen, S. (1998). Citizenship and the ethics of care: Feminist considerations on justice, morality and politics. London: Routledge.

Sevenhuijsen, S. (2000). Caring in the third way: The relation between obligation, responsibility and care in third way discourse. Critical Social Policy, 20(1), 5-37.

Skoe, E. E. A., Cumberland, A., Eisenberg, N., Hansen, K., \& Perry, J. (2002). The influences of sex and genderrole identity on moral cognition and prosocial personality traits. Sex Roles, 46(9), 295-309.

Taylor, C. (1994). The politics of recognition. In A. Gutmann (Ed.), Multiculturalism: Examining the politics of recognition (pp. 25-73). Princeton, NJ: Princeton University Press.

Tronto, J. C. (1993). Moral boundaries: A political argument for an ethic of care. London: Routledge.

Tronto, J. C. (2013). Caring democracy: Markets, equality, and justice. New York, NY: New York University Press.

Vollmer, B., \& Karakayali, S. (2018). The volatility of the discourse on refugees in Germany. Journal of Immigrant \& Refugee Studies, 16(1/2), 118-139.

Williams, F. (2001). In and beyond New Labour: Towards a new political ethics of care. Critical Social Policy, 21(4), 467-493.

Young, I. M. (1990). Justice and the politics of difference. Princeton, NJ: Princeton University Press.

Zembylas, M., \& Bozalek, V. (2011). The Council of Europe's white paper on intercultural dialogue: An analysis using the ethic of care. Policy Futures in Education, 9(1), 13-21.

\section{About the Author}

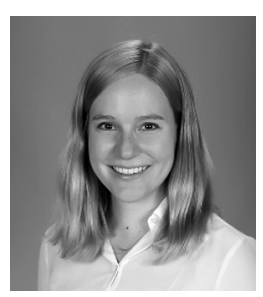

Sophia Schmid is a PhD candidate in Political Science at the Berlin Institute for Integration and Migration Research (BIM) at Humboldt University of Berlin in Germany. She completed a Master of Science in Culture and Society at the London School of Economics and Political Science in 2014. Using an interdisciplinary approach, she combines sociology, postcolonial, feminist and cultural studies and social psychology. Her research interests include negotiations of diversity and difference, the construction of shared and exclusive identities and the nexus between gender, migration and refugees. 